\title{
Pendampingan Pengembangan Inovasi Desain Kelompok Rajut Sejahtera Kotabaru, Yogyakarta
}

\author{
Centaury Harjani ${ }^{1}$, Koniherawati ${ }^{2}$, Anesti Budi Ermerawati ${ }^{3}$, Dan Daniel Pandapotan ${ }^{4}$ \\ Desain Produk, UKDW \\ Jl.Dr.Wahidin Sudirohusodo no.5-25, Yogyakarta \\ ${ }^{1}$ centaury_h@staff.ukdw.ac.id \\ ${ }^{2}$ koni_hrwt@staff.ukdw.ac.id \\ 4danpandapotan@staff.ukdw.ac.id \\ Pendidikan Bahasa Inggris, Fakultas Kependidikan dan Humaniora, UKDW \\ Jl.Dr.Wahidin Sudirohusodo no.5-25, Yogyakarta \\ 3ermerawati@staff.ukdw.ac.id
}

\begin{abstract}
Abstrak - Kelompok Rajut Sejahtera atau Kelompok Ratra yang berdiri pada tahun 2016 merupakan kelompok ibu rumah tangga istri pensiunan tentara yang gemar merajut. Bertempat tinggal di perumahan tentara Kotabaru Yogyakarta, kelompok Ratra telah mengikuti beberapa kegiatan pembinaan untuk pelatihan merajut produk seperti tas, dompet, dan sepatu yang bertujuan menambah pengetahuan dan pemasukan keluarga. Pemasaran produk sudah dilaksanakan sejak tahun 2019, namun hasil penjualan belum baik dikarenakan adanya persaingan produk sejenis di pasaran. Di tahun 2021 ini, tim UKDW memfasilitasi kelompok Ratra dalam berinovasi desain dan menemukan karakter produk rajut untuk bersaing dalam pemasaran serta membuka pangsa pasar baru yang belum banyak dibuat oleh kompetitor sejenis, khususnya menghadapi situasi pandemik ini. Melalui pendampingan workshop, kelompok Ratra diperkenalkan dengan inovasi desain produk seperti bentukbentuk produk tableware, home decoration, serta aksesoris berukuran kecil yang cepat dibuat dan dibutuhkan dalam keseharian calon konsumen. Pendampingan difokuskan pada workshop kreativitas sekaligus penemuan ciri khas produk Ratra agar lebih cepat dikenal dan disukai konsumen. Adapun workshop yang diberikan antara lain perancangan kemasan, prinsip-prinsip desain, pemahaman tutorial desain rajut berbahasa Inggris, serta pengenalan alternatif material rajut dan penerapannya. Hasil utama dari pendampingan ini adalah penambahan wawasan pengetahuan varian produk rajut serta membangun peluang pasar baru dengan pengembangan jenis produk kelompok Ratra.
\end{abstract}

Kata kunci-Inovasi desain, produk rajut, desain berkarakter, peluang pasar.

Abstract - Established in 2016, Rajut Sejahtera Community or so-called Ratra, a crochet community that was supported by the wives of retired soldiers in Kotabaru Yogyakarta, has equipped themselves with intensive practices on different crochet products such as bags, purses, and shoes. As their product marketing conducted in 2019 did not result in good economic income, the UKDW community service team proposed community mentoring to win the market better than before, with a concern of during-pandemic situation. Introducing product design innovation, the team is arranging a set of workshops focusing on tableware, home decoration, as well as simple-daily-used crochet products. The workshops meetings designed for honing creativity on Ratra's distinctive crochet pieces cover packaging design, design principles, crochet tutorial videos in English, and an introduction to kinds of crochet materials as well as using them in crocheting. By the end of the mentoring program, Ratra community members are expected to be empowered to broaden their knowledge on various crochet-based products as well as gaining the market with their updated crochet products.

Keywords - design innovation, crochet-based products, design characterization, market opportunity

\section{PENDAhuluan}

Kelompok rajut sejahtera (Ratra) merupakan kelompok rajut yang beranggotakan ibu-ibu rumah tangga dengan hobi merajut. Mereka bersama-sama membentuk kelompok untuk menambah penghasilan melalui produk-produk rajut. Kelompok ini memiliki harapan untuk dapat bersaing dengan competitor rajut yang maju di Yogyakarta. Beragam pelatihan telah diikuti oleh kelompok rajut ini. Bantuan dari berbagai pihak berupa mesin jahit disertai pelatihan penggunaan mesin dalam menyelesaikan rajutan telah diterima oleh kelompok ini. Hal lain yang perlu diketahui oleh kelompok ini adalah kemampuan merancang dalam mengembangan produk rajut. 


\section{METODE PELAKSANAAN}

Metode workshop digunakan untuk memberikan wawasan kemampuan merancang pengembangan inovasi desain produk bagi kelompok rajut sejahtera. Workshop digunakan sebagai cara mentransfer pengetahuan kepada ibu-ibu kelompok rajut. Workshop yang dilakukan adalah secara hybrid yaitu menggabungkan kegiatan daring dan luring secara bergantian. Workshop juga dilakukan dengan kolaborasi dari dua Program Studi, UKDW. Pendekatan experiential learning (EL) yang secara pedagogik mengedepankan prinsip "learning by doing" menjadi pendekatan utama yang digunakan selama kegiatan.

Adapun rangkaian kegiatan pengembangan inovasi desain ini adalah sebagai berikut:

1. Pertemuan luring dalam melakukan penjajakan dan perkenalan

Tanggal: Mei 2021

2. Pembuatan Label (kulit dan kain) Tanggal: Juni 2021

3. Pelaksanaan workshop secara daring Tanggal: 28 Juni, 22 Juli, \& 23 Juli 2021

\section{KAJIAN LITERATUR}

Susan Haws dan Debora Proctor [1] memberikan pemahaman mengenai pengembangan rajut juga terdapat beberapa panduan yaitu:

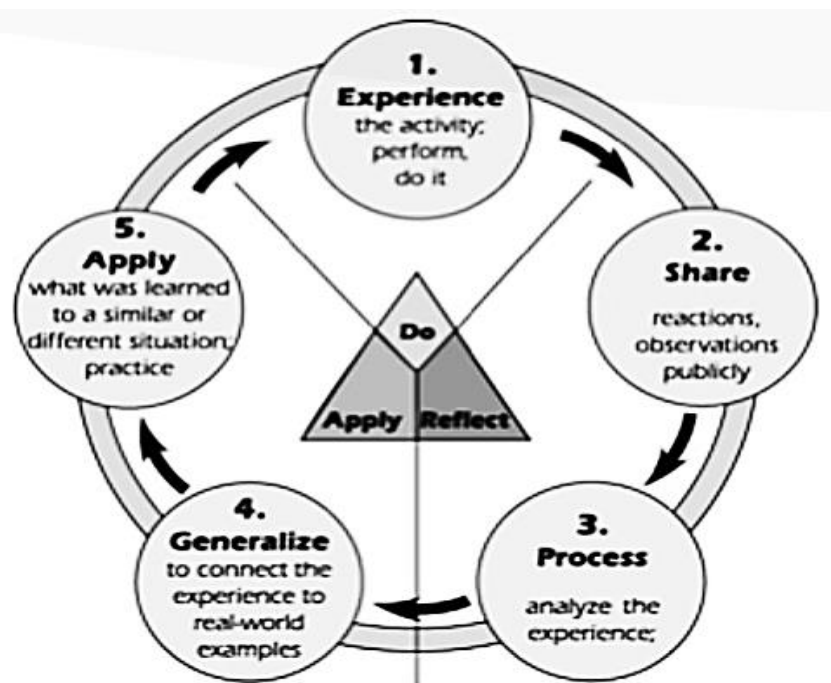

Gambar 1. Tahapan yang perlu diperhatikan dalam pengembangan produk rajut.

Shannon Beatty [2] juga menyebutkan bahwa diperlukan kemampuan untuk mengembangankan keahlian dalam merajut, berikut pernyataannya:
"In addition to a comprehensive guide to basic stitches and techniques, Crochet provides an extensive gallery of stitch textures, crocheted edgings, openwork, and colorwork, as well as a guide to making granny squares and stunning flowers, all with patterns. Use these to build on your basic crocheting skills, before embarking on more adventurous and impressive crochet patterns, and you will find yourself equipped to create any project in the book!'”2].

Pengetahuan mengenai prinsip-prinsip desain dasar dapat diberikan menjadi landasan kelompok dalam mengembangkan produk. Adapun beberapa prinsip desain yang perlu dimiliki antara lain pengetahuan mengenai:

1. Warna dan kombinasinya

2. Material, kombinasi, dan penerapannya

3. Prinsip pembentukan citra/ciri khas produk

4. Kreatifitas pengembangan bentuk produk

\section{DISKUSI PELAKSANAAN}

Pelaksanaan workshop dilakukan secara daring menggunakan komunikasi melalui WhatsApp (WA Group). Aplikasi ini dipilih karena sudah biasa digunakan oleh ibuibu anggota kelompok rajut yang sudah berusia lanjut. Penggunakan WA memudahkan komunikasi maupun untuk aktifitas tanya jawab. Materi-materi dibuat dengan menggunakan video pembelajaran yang dibagikan dalam format $\mathrm{mp} 4$ atau video unggahan melalui YouTube Pelaksanaan kegiatan ini terdiri dari empat topik utama, yaitu:

\section{A. Prinsip Desain Warna dan Kombinasinya}

Ada banyak prinsip-prinsip di dalam mengembangkan inovasi sebuah produk, beberapa prinsip desain yang penting dan relevan untuk diketahui oleh ibu-ibu kelompok Rajut Sejahtera adalah mengenai prinsip warna dan kombinasinya. Pengetahuan dasar tentang warna dapat memberikan keunikan yang berbeda dari produk-produk yang sudah ada di pasaran.

Prinsip-prinsip warna yang ada beberapa jenis warna antara lain:

- Warna Primer: merupakan warna-warna dasar (merah, kuning, biru).

- Warna Sekunder: merupakan warna-warna gabungan dari dua warna primer (oranye, hijau, ungu) 
- Warna Tersier: merupakan warna-warna penggabungan dari dua warna sekunder.

- Warna Netral: sebagai warna pengikat untuk menggabungkan beberapa warna (puith, hitam, abuabu)

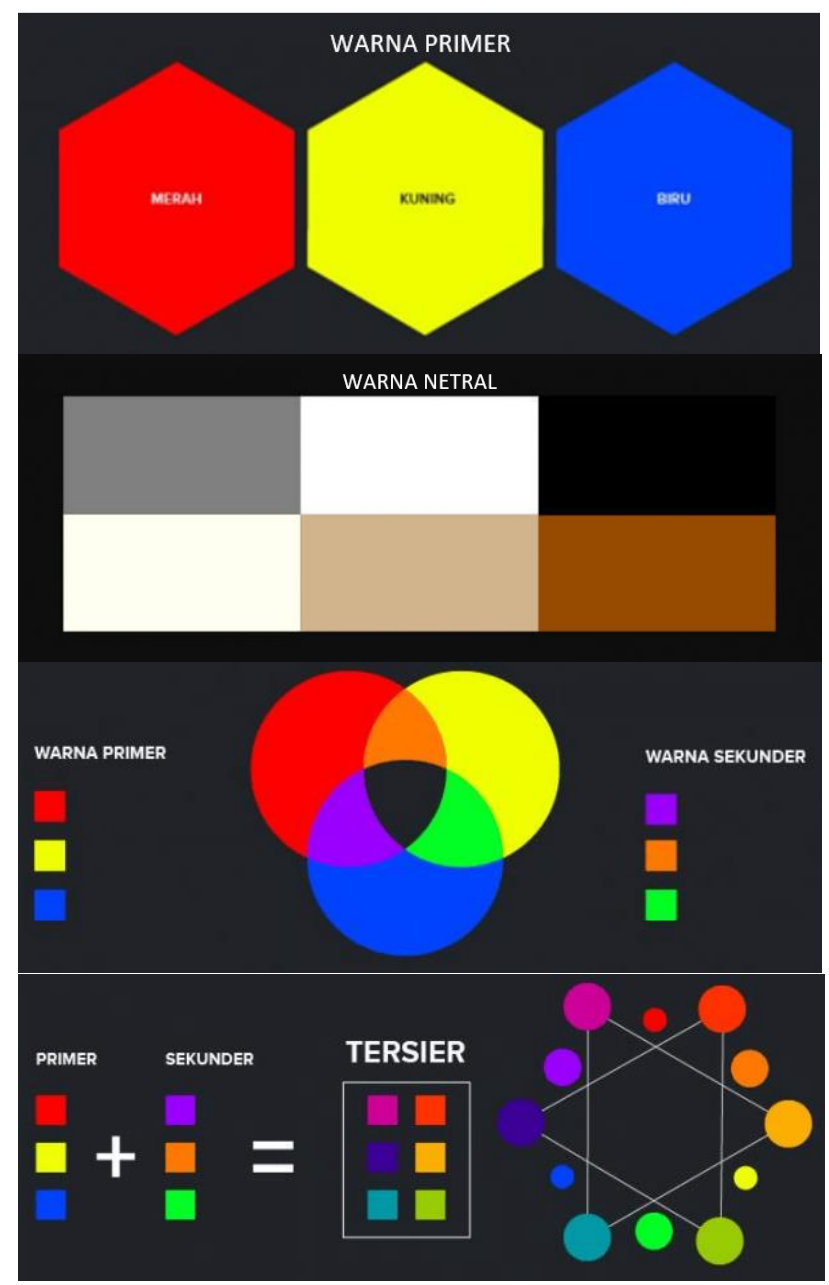

Gambar 2. Jenis-jenis Warna

Prinsip kombinasi warna juga ada beberapa yaitu:

- Kontras: penggunaan kombinasi dua warna yang saling berhadapan pada roda warna.

- Analogous: penggunaan kombinasi tiga warna yang berderetan pada roda warna.

- Triadic: penggunaan kombinasi tiga warna yang jaraknya sama pada roda warna.

- Rectangular: penggunaan kombinasi empat warna yang jaraknya sama pada roda warna.

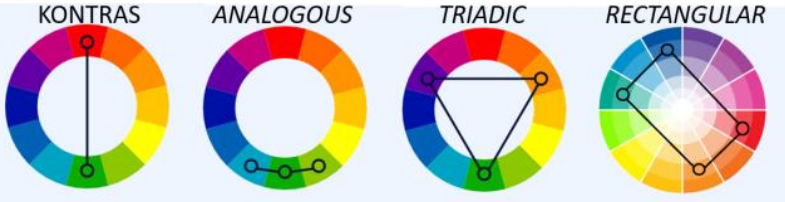

Gambar 3. Kombinasi warna berpatokan dari roda warna

Pemilihan warna juga dapat memperhatikan arti dari warna yang dipilih, seperti:

- Merah: Peringatan, Kewaspadaan, Tidak stabil, Energi, Gairah

- Oranye: Kesenangan, Kesegaran, Antusias, Kreatif, Pembaharuan

- Kuning: Keceriaan, Kegembiraan, Kehangatan-, Kehidupan, Energi

- Hijau: Kesuburan, Pertumbuhan, Kesegaran, Pembaharuan, Kestabilan.

- Biru: Damai dan tenang, Loyalitas, Kebijaksanaan, Intelektual, Kebesaran/kekuasaan.

- Ungu: Misterius, Spiritual, Keanggunan, Bernilai, Kemewahan, Kebijaksanaan.

- Cokelat: Natural, Hangat, Kuat, Tahan lama.

- Pink: Romantis, Feminim, Ceria, Energik.

- Hitam: Elegan, Canggih, Simple, Misterius, Kuat.

- Putih: Bersih, Murni, Simple, Luas.

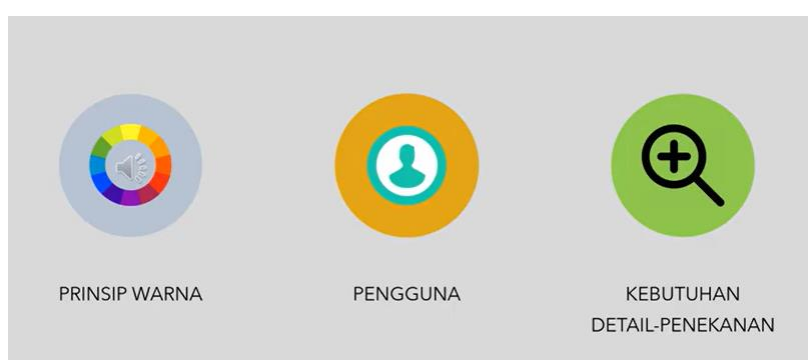

Gambar 4. Prinsip selain warna yang penting diketahui dalam materi desain dalam unggahan youtube Centaury [3]

Selain prinsip warna pengetahuan mengenai pengguna dan detail penekanan perlu diketahui oleh ibu-ibu kelompok Rajut Sejahtera. Informasi terkait pengguna seperti usia, jenis kelamin, pekerjaan, hobi, adat istiadat, kebiasaan, hingga kemampuan daya belinya perlu diketahui diawal sebelum akan menentukan pengembangan suatu inovasi produk rajut. Kebutuhan detail penekanan pada suatu produk juga dapat menjadi salah satu pertimbangan dalam mengembangkan produk, yaitu merancang inovasi produk-produk rajut sebagai detail pelengkap dari sebuah produk.

B. Prinsip Desain Material, Kombinasi, \& Penerapannya 
Material merupakan salah satu aspek penting yang sangat patut untuk dilirik sebagai salah satu focus dalam pengembangan suatu produk. Hal ini sejalan dengan pernyataan dari Michael F. Ashby dan Kara Johnson yaitu "We live in a world of materials; it is materials that give substance to everything we see and touch" [4]. Material rajut atau dikenal dengan sebutan yarn memiliki bentuk gulungan. Jenis material yang paling dikenal adalah wool yang biasa terbuat dari bulu domba. Bulu domba yang telah dibersihkan diolah menggunakan alat pintal. Alat ini mengubah bentuk dasar material yang semula menggumpal menjadi jalinan tali yang tidak terputus. Jalinan bisa terbentuk dikarenakan material tersebut memiliki karakteristik serat yang dapat diatur searah ketika mengalami perlakuan mekanis putar saat dipintal. Meski teknologi pemintalan sudah ada sejak lama, konsep pemintalan tidak banyak mengalami perubahan. Salah satunya pada kekuatan pintalan yang mempengaruhi ikatan yarn, menurut Noah dan Whewell jika pintalan terlalu kencang atau terlalu banyak, maka akan berakibat ikatan yarn terputus [5].

Teknologi pemintalan yang ada saat ini telah mampu membuat yarn menjadi berbagai varian. Varian umumnya terdiri dari warna, ketebalan dan jenis material. Khusus pada jenis material, terdapat 3 komposisi dasar yang digunakan oleh produsen, yaitu murni serat alam, murni serat sintetis dan campuran antara serat alam dan sintetis. Semakin tinggi kadar serat alam, maka semakin kuat jalinan yarn. Sebaliknya, semakin tinggi kadar serat sintetis, maka semakin lemah jalinan yarn. Namun, pada beberapa kasus terdapat serat sintetis yang dibuat dengan cara mengadopsi bentuk jalinan serat alam menjadi beberapa helai dengan tujuan memperkuat struktur.

Contoh bahan yarn alami adalah katun yang terbuat dari tumbuhan, dan wool yang terbuat dari rambut hewan. Wool memiliki ciri visual berupa serabut dan berpori sehingga dapat menyerap bahan pewarna dengan baik dan menghasilkan warna yang cerah. Contoh bahan yarn buatan adalah nylon dengan ciri hydrophobic yang tidak menyerap banyak air, polyester dengan ciri kuat, tahan penyusutan, tahan tarik, tahan kerutan yang diperoleh dari percamuran dengan bahan lain, dan spandex dengan ciri lentur.

Terdapat 3 jenis bahan yang digunakan sebagai contoh perbandingan pembuatan yarn. Pertama, plastik yang berasal dari kresek bekas. Kedua, kain yang berasal dari kaos bekas. Ketiga, kertas yang berasal dari kertas minyak atau kertas roti.Secara garis besar, pembuatan bahan yarn menggunakan material alternatif dapat dilakukan melalui 3 tahap. Tahap pertama, persiapan mengumpulkan, memilah, membersihkan dan mengukur bahan. Tahap kedua, pemotongan dengan penggaris atau tanpa penggaris. Tahap ketiga, pemilinan dengan tangan atau alat bantu.

Material alternatif pertama yang digunakan, yaitu plastik yang berasal dari kresek. Adapun hal yang perlu diperhatikan adalah ketika proses memilin, sebaiknya disertai dengan tarik-ulur layaknya ketika tarik-ulur benang pancingan. Hal ini dilakukan untuk mengunci pilinan dan mengurangi sifat elastis plastik sehingga pilinan dapat terkunci dengan kokoh, karena Siti Haryati, Widowati, dan Urip Wahyuningsih mengatakan bahwa "helaian plastik yang di pilin akan terus menolak dan berusaha kembali ke bentuk semula" [6]. Material alternatif kedua yang digunakan, yaitu kain yang berasal dari kaos pakaian. Adapun hal yang perlu diperhatikan adalah kadar serat alami bahan. Secara umum, semakin tinggi kadar katun, maka karakter kain akan semakin regas atau mudah putus, tetapi, jika kadar polyester semakin tinggi, maka kain semakin kuat. Selanjutnya, pada pembuatan pola potong sebaiknya mengikuti arah serat melebar ke samping, bukan arah atas-bawah, hal ini dikarenakan tekstil dirancang untuk lebih tahan tarikan melebar ke samping jika dibandingkan tarikan atas-bawah.Material alternatif ketiga yang digunakan, yaitu kertas yang berasal dari kertas minyak atau kertas roti. Adapun hal yang perlu diperhatikan adalah kekuatan jalinan. Kertas yang kuat adalah kertas yang memiliki campuran bahan plastik. Ciri-ciri fisiknya, yaitu yarn akan terlihat sedikit mengkilap. Sedangkan kertas yang tidak mengkilap atau tidak memiliki serat sejajar memiliki kekuatan yang rendah atau biasa disebut regas.

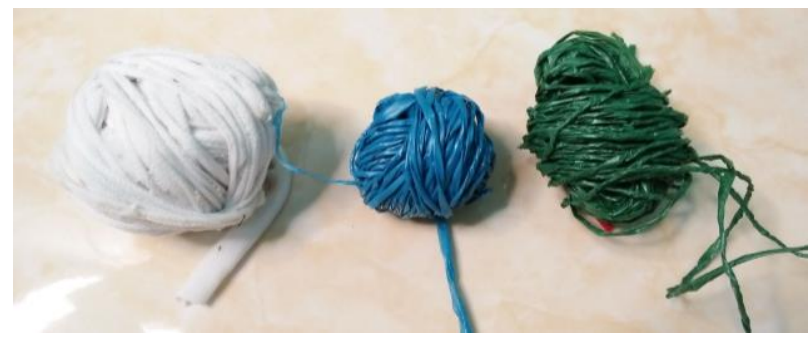

Gambar 5. (Dari kiri ke kanan) Yarn yang terbuat dari material kain, plastik, dan kertas.

\section{Prinsip Pembentukan Citra/Ciri Khas Produk}

Pembentukan citra/ciri khas produk dapat diperoleh melalui brand yang jelas. Salah satunya adalah melalui perancangan kemasan produk yang berbeda dari kemasan produk sejenis dipasaran. Kemasan sering dianggap sepele oleh produsen dalam menjual produknya, khususnya untuk kalangan usaha kecil menengah (UKM) yang biasa menggunakan bungkus 
seadanya seperti kertas Koran atau tas plastik kresek yang mudah ditemui dan relatif murah harganya. Ibu-ibu kelompok Ratra selama ini lebih fokus memikirkan cara produksi produknya saja.

Namun, kenyataannya kemasan perlu didesain sedemikian rupa agar menciptakan identitas perusahaan atau produk. Kemasan yang baik merupakan kesatuan dari branding agar mudah diingat konsumen dan dapat menarik konsumen untuk membeli produk, bahkan akan menjadi media promosi langsung (direct promotion) dari seseorang pembeli agar mudah dilihat saat membawa produk dan memiliki daya persuasif agar orang yang melihat itu jadi ingin ikut membeli produk dari perusahaan tersebut. Dengan demikian maka dalam pendampingan oleh Tim UKDW ini dikenalkan juga pentingnya desain kemasan (packaging) sebagai kesatuan branding produk rajut Ratra.

Pengertian Desain kemasan (packaging) adalah sesuatu yang berhubungan dengan perancangan pembuatan wadah atau pembungkus suatu produk untuk melindungi produk selain dari debu juga melindungi pada saat distribusi (membawa atau pengiriman), penyimpanan, penjualan dan lainnya. Adapun manfaat atau fungsi kemasan, antara lain sebagai berikut:

1. Perlindungan Fisik, terhadap guncangan, getaran, suhu udara, kelembaban dan dari debu.

2. Pemasaran. Kemasan yang tepat dan menarik mempunyai peran penting dalam mendorong atau mempengaruhi calon konsumen (pembeli).

3. Kenyamanan, mempunyai fitur yang menambah kenyamanan dalam distribusi, tampilan dan penggunaan (membawa).

Kemasan termasuk dalam strategi pemasaran produk, khususnya dalam strategi promosi. Kemasan berhubungan dengan marking dan labelling yang keduanya merupakan unsur penting dalam branding. Yang disebut dengan marking adalah tanda-tanda yang harus menempel (dipasang) pada kemasan suatu produk (barang).
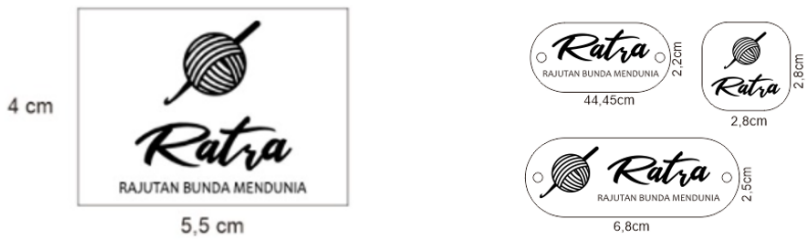

Gambar 6. Desain Beserta Ukuran label Produk Ratra

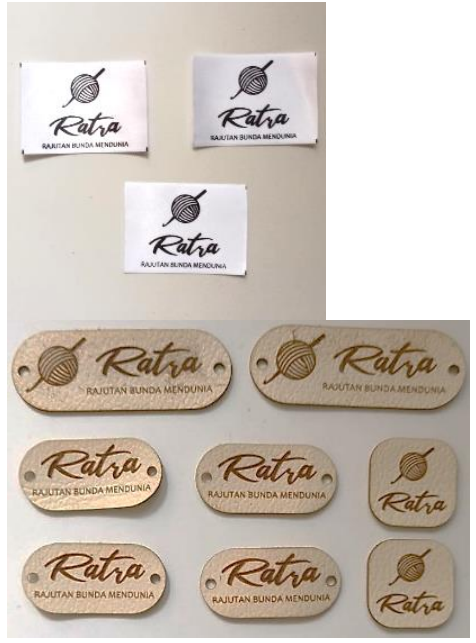

Gambar 7. Label Produk Ratra

Sedangkan labelling merupakan kertas bergambar dan bertuliskan, misalnya menggambarkan barang berbahaya yang ditempel pada kemasan. Penempelan labeling perlu diperhatikan agar mudah dibaca dan dilihat serta harus jelas atau tidak kabur. Cara menempelnya perlu kuat dan ukurannya sesuai aturan yang berlaku. Labelling diperlukan khususnya sebagai petunjuk saat distribusi, terlebih untuk barang (produk) yang mudah pecah atau rusak, berupa cairan atau lainnya.
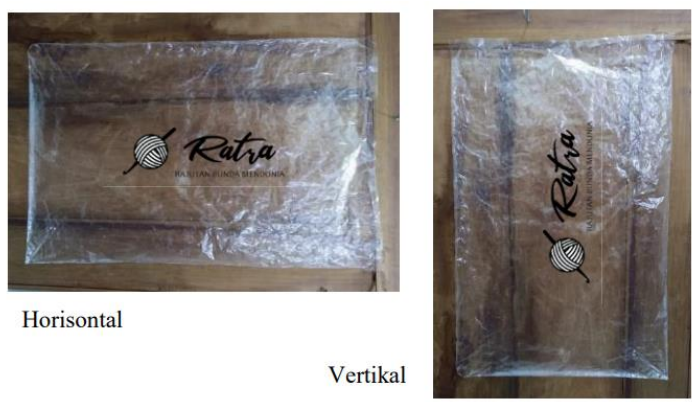

Gambar 8. Pengembangan Desain Baru Kemasan Ratra

Kemasan dapat berupa tas, kotak, bungkus dan lainnya. Bahannya juga bermacam-macam, seperti karton (kardus), plastik, kaleng dan lainnya tergantung produk yang akan dikemas dan fungsi kemasan itu sendiri. Setelah beberapa kali dilakukan kunjungan dan diskusi dengan kelompok Ratra, maka ditawarkan beberapa desain kemasan yang lebih menarik, komunikatif atau persuasif serta tidak sekali pakai tetapi ada konsep reuse. 

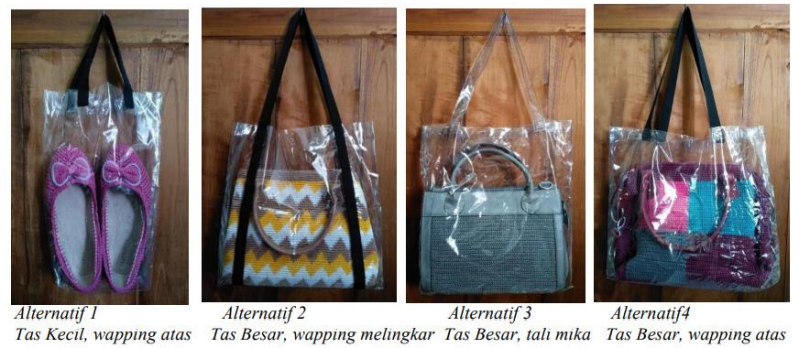

Gambar 9. Alternatif Desain Kemasan Ratra Baru

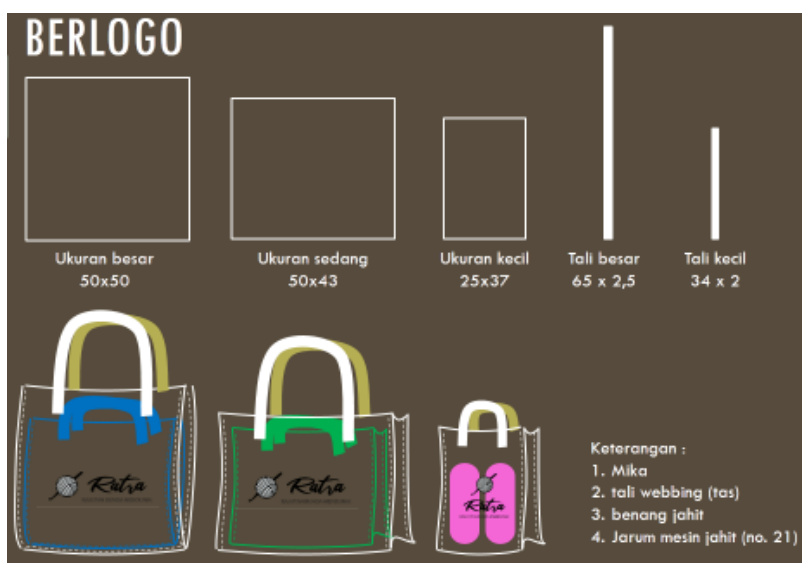

Gambar 10. Pola dan Ukuran Desain Kemasan Ratra Baru
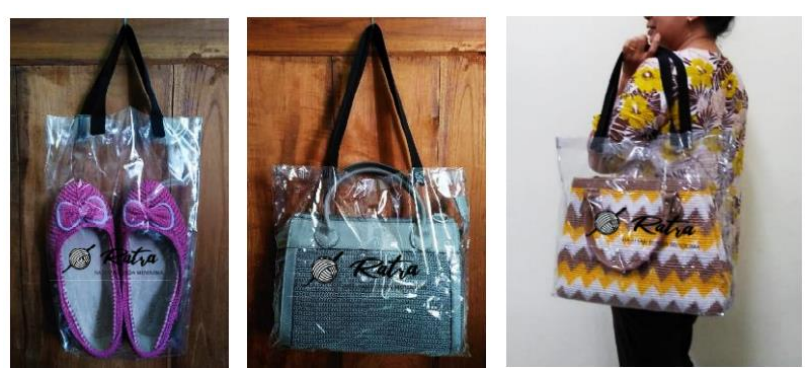

Gambar 11. Desain Kemasan Ratra Terpilih

Melalui perbaikan dalam desain kemasan ini diharapkan akan membantu produk rajut Ratra lebih dikenal luas dan dapat menjadi strategi pemasaran dalam meningkatkan penjualan. Situasi pandemic Covid 19 ini menjadikan jadwal workshop tentang desain kemasan yang sedianya akan dilakukan secara tatap muka (offline) menjadi daring (on-line). Keinginan belajar para ibu-ibu di kelompok rajut Ratra tidak melemah walaupun acara workshop dilakukan secara daring, kemajuan teknologi digital sangat membantu kami dalam transfer pengetahuan tentang kemasan ini. Kemasan yang disarankan untuk dikembangkan ibu-ibu kelompok rajut adalah kemasan yang sekaligus berfungsi sebagai media promosi produk raut dari ibuibu kelompok Ratra. Berikut adalah beberapa produk Rajut Ratra dan kemasan lama:

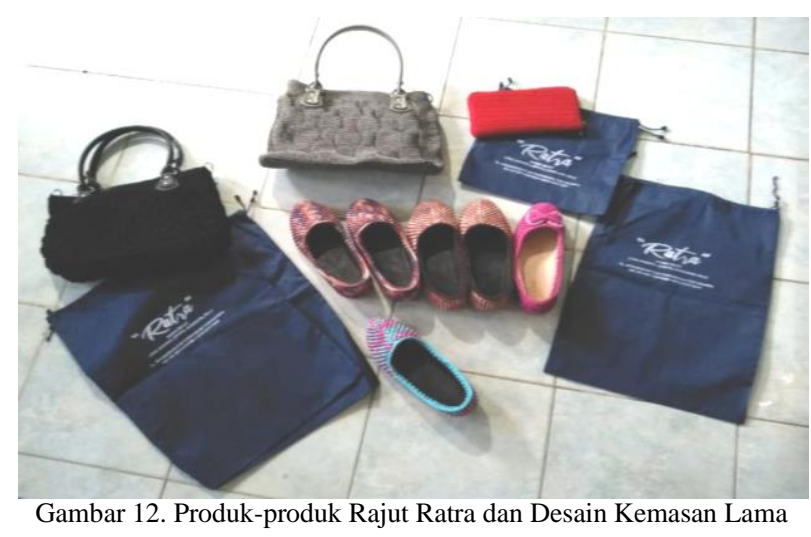

\section{Kreatifitas Pengembangan Bentuk Produk}

Tujuan mengembangkan kreatifitas pengembangan inovasi produk rajut perlu didukung dengan sumbersumber belajar yang tersedia dalam jangkauan kelompok rajut ini, salah satunya video tutorial yang tersedia dalam platform YouTube. Salah satu tantangan dalam memahami tutorial dalam mengikuti tutorial tersebut adalah memahami bahasa Inggris yang digunakan sebagai bahasa pengantarnya. Karena bahasa Inggris merupakan bahasa asing bagi anggota kelompok Ratra, diperlukan program pendampingan yang membantu memberdayakan kemampuan bahasa Inggris mereka dalam memahami video tutorial YouTube secara mandiri dalam rangka menambah pengetahuan mereka akan keragaman desain rajutan.

Sesi ketiga pada tanggal 23 Juli 2021 dalam rangkaian program Pengabdian kepada Masyarakat (PkM) ini, Anesti Budi Ermerawati, S.Pd., M.Hum. berkesempatan memaparkan sesi mini workshop berjudul "Let's Crochet" yang menggunakan pendekatan experiential learning (EL). EL yang secara pedagogik dikatakan oleh Kotti [7] mengedepankan prinsip "learning by doing" ini menfasilitasi peserta program PkM menguasai pemahaman dalam berkreasi dengan rajutannya setelah mengalami proses pembelajaran yang baru. Tidak hanya menekankan pada pemerolehan pengalaman, EL juga memberikan pandangan dan sikap positif akan sebuah proses pembelajaran seperti pendapat dari Mezirow [8]. Pendampingan berbasis EL ini terkait erat dengan metode pembelajaran berbasis proyek. Chrisafidis [9] mengatakan pendekatan EL dalam sebuah kelas secara pedagogis dapat meningkatkan kegiatan praktik secara langsung daripada kegiatan pasif teoritis serta mengedepankan kepercayaan diri dan kemandirian peserta selepas program PkM. Dengan pembelajaran yang sifatnya mengembangkan pengetahuan merajut yang peserta miliki, sesi PkM ini menggabungkan konteks pembelajaran dengan kebutuhan para peserta 
untuk mengembangkan desain rajutannya. Indikator ketercapaian pembelajaran seperti (1) peserta mengucapkan kosakata merajut berbahasa Inggris, (2) peserta mempresentasikan Gerakan tusukan merajut yang diinstruksikan dalam bahasa Inggris dengan benar, serta (3) membuat sebuah proyek merajut sederhana dengan mengikuti video tutorial berbahasa Inggris dari kanal YouTube menjadi tanda tercapainya sesi PkM ini. Hal ini menyesuaikan dengan kondisi pandemi yang tengah melanda Kota Yogyakarta dan kebijakan Pemberlakuan Pembatasan Kegiatan Masyarakat (PPKM) yang diberlakukan, sesi ini dilakukan secara daring menggunakan platform WhatsApp (WA) sebagai media komunikasi dan YouTube Let's Crochet oleh Ermerawati [10] sebagai media pemaparan materi.

Setelah merespon laman presensi dan pre-test, peserta mini workshop diberi waktu 60 menit untuk menyaksikan paparan materi pada kanal YouTube hingga mencoba mengerjakan proyek merajut alas gelas dari video tutorial berbahasa Inggris, dan kembali pada diskusi kelompok dalam WA. Dalam paparan materi, peserta dipersiapkan untuk siap mengikuti video tutorial merajut alas gelas sederhana berbahasa Inggris pada kanal YouTube How to Crochet a Coaster oleh Coco [7]. Guna mengeksplorasi variasi desain, peserta sesi diarahkan untuk mencoba pola rajutan dengan jenis benang goni untuk memberi kesan etnik pada produk akhir proyek. Beberapa peserta yang walaupun belum memiliki benang goni, berhasil mengikuti video tutorial membuat alas gelas berbahasa Inggris dengan baik. Hal tersebut diafirmasi dengan hasil post-test yang lebih baik. Sesi berbasis EL ini diharapkan dapat memberdayakan anggota kelompok Ratra mengembangkan desain rajutannya.
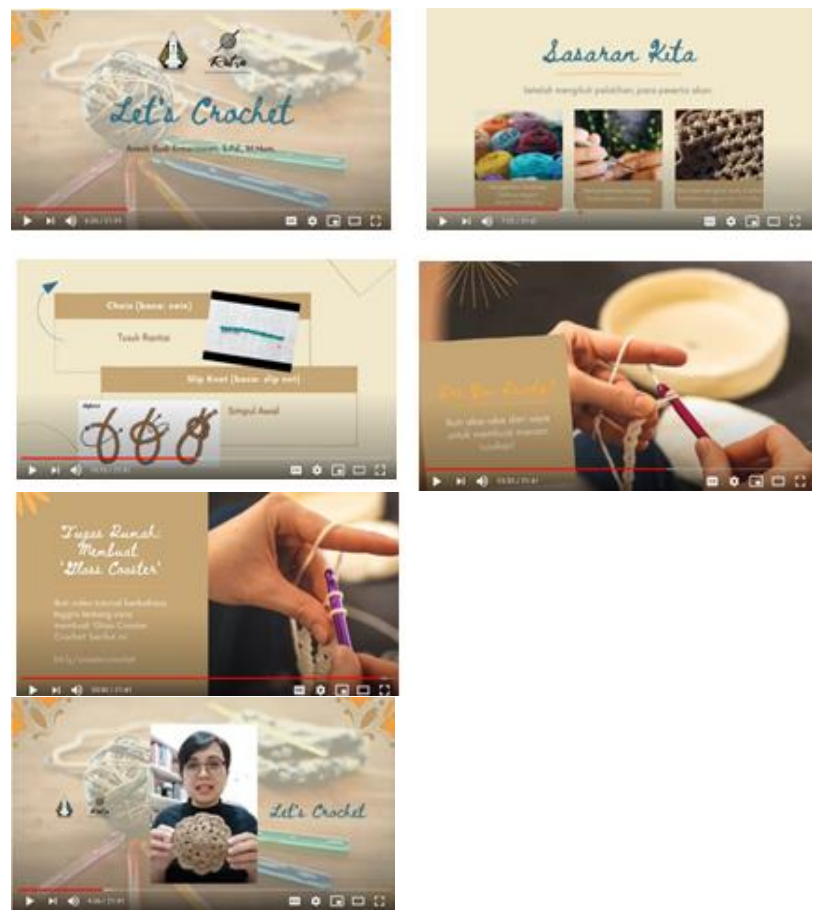

Gambar 13. Materi Sesi Mini Workshop "Let's Crochet"

V. HASIL INOVASI PENGEMBANGAN PRODUK

Pendampingan pengembangan inovasi produk rajut telah menghasilkan produk hasil praktik berupa coster, hasil menerapkan Teknik perwujudan sesuai tutorial dari YoutTube. Kreasi yang dilakukan adalah pada kombinasi warna-warni yang belum pernah dicoba sebelumnya, juga menerapkan penggunaan material alami yaitu tali goni, serta membuat kreasi pengembangan coaster menjadi alas pot serta taplak untuk dekorasi meja.

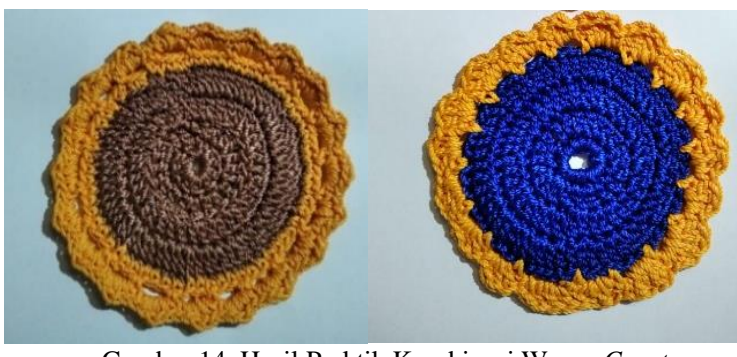

Gambar 14. Hasil Praktik Kombinasi Warna Coaster 


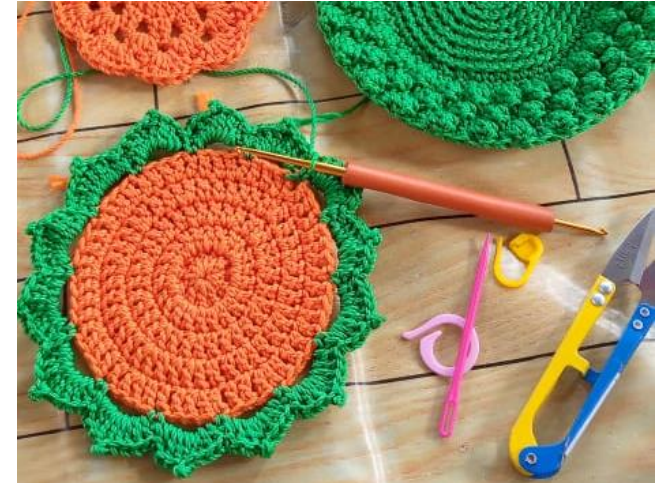

Gambar 15. Hasil Praktik Kombinasi Warna Hijau dan Jingga

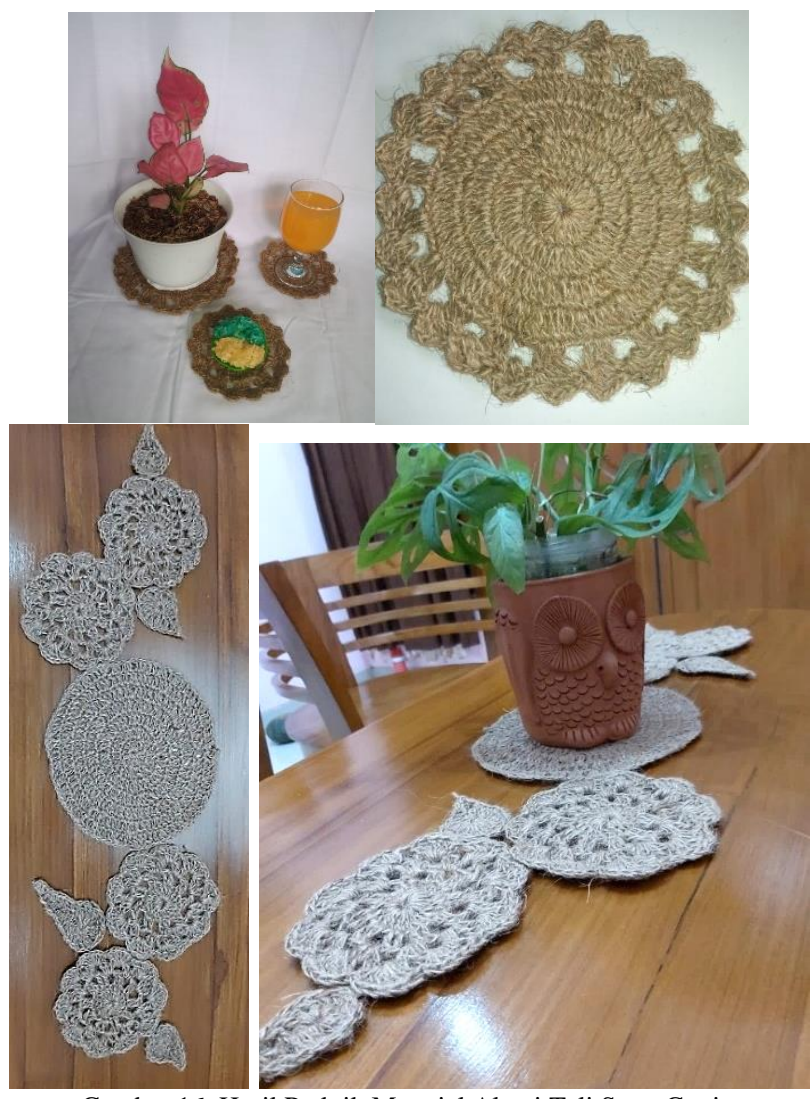

Gambar 16. Hasil Praktik Material Alami Tali Serat Goni

\section{KESIMPULAN}

Kemampuan merancang dari segi desain seperti penggunaan warna dan material berbeda dapat dijadikan nilai kebaharuan dari produk Ratra. Ibu-ibu kelompok Rajut Sejahtera telah mencoba memadupadankan beberapa warna-warni yang berbeda serta diajak untuk melirik kategori jenis produk lain diluar yang biasa dibuat. Produk seperti tatakan gelas, tatakan piring, tatakan pot hingga taplak dekorasi meja telah diketahui dapat dimasukan sebagai produk rajut kelompok Ratra.
Tahapan selanjutnya yang perlu terus dilakukan adalah berlatih mencoba beragam kreasi rajut yang berbeda, meningkatkan kualitas hasil rajut, serta meningkatkan semangat maupun rasa percaya diri ibu-ibu kelompok rajut untuk memasarkan produk-produknya.

\section{UCAPAN TERIMA KASIH}

Ucapan terima kasih kami berikan pada Fakultas Arsitektur dan Desain serta pada LPPM Universitas Kristen Duta Wacana yang telah mendukung dalam hal pendanaan maupun dukungan kepercayaan yang diberikan sehingga PkM di kelompok Rajut Sejahtera dapat berjalan dengan baik.

\section{DAFTAR PUSTAKA}

[1] Haws, Susan \& Debra Proctor., The 4-H Crocheting Handbook. Utah: Utah State University Cooperative Extension, 2012.

[2] Beatty, Shannon, Crochet: The Complete step-bystep guide Essential Technique More than 80 Crochet Patterns. New York: DK Publishing, 2014.

[3] Harjani, Centaury H. (2021) Design [online]. Available:https://www.youtube.com/watch?v=dVJ5 OW0Wsww

[4] Ashby, M. F., \& Johnson, K., Materials and Design: The Art and Science of Material Selection in Product Design. $3^{\text {rd }}$ Edition. United of Kingdom: Butterworth-Heinemann, 2014.

[5] Abrahart, E. Noah and Whewell,. Charles S. (2020, June 4). "Textile” Encyclopedia Britannica [online]. Available: https://www.britannica.com/topic/textile.

[6] Haryati, S., Widowati, \& Wahyuningsih, U., "Kualitas Hasil Tenunan Kantong Plastik Bekas antara Teknik Pilin dan Teknik Lipat", Fashion and Fashion Education Journal, 1(1), 2012.

[7] Kotti, D., "Experiential Learning from Theory to Practice”, Adult Education, 13, 35-41, 2008.

[8] Mezirow, J., Transformative Dimensions of Adult Learning. San Francisco: Jossey-Bass, 1991.

[9] Crisafidis, K., Experiential-Communicative Teaching. Implementing The Project Method in School. Athens: Gutenberg, 2005.

[10] Ermerawati, E. (2021). Let's Crochet [online]. Available: https://www.youtube.com/watch?v=3zCUAru-A9I 